\title{
Correction to: Ankle CT scan allows better management of posterior malleolus fractures than $\mathrm{X}$-rays
}

\author{
Pierre-Alban Bouche ${ }^{1}$ (D) Nicolas Gaujac ${ }^{1}$. Simon Corsia ${ }^{1} \cdot$ Philippe Leclerc $^{2} \cdot$ Philippe Anract $^{1}$. \\ Guillaume Auberger ${ }^{2}$
}

Published online: 5 October 2021

(c) Springer-Verlag France SAS, part of Springer Nature 2021

\section{Correction to: \\ European Journal of Orthopaedic Surgery \& Traumatology https://doi.org/10.1007/s00590-021-03104-y}

The original version of this article unfortunately contained a mistake. The wrong figure appeared as Fig. 1. The corrected Fig. 1 is given below.

Fig. 1 Percentages of posterior malleolar injury on X-rays and on CT scan. On the left side, the graph represents the percentage of posterior malleolar injury on $\mathrm{X}$-rays. On the right side, the graph represents the percentage of posterior malleolar injury on CT scan. The y-axis is the percentage. The red box illustrates the rate of ankle fracture with a posterior malleolar injury. The blue box illustrates the rate of ankle fracture without a posterior malleolar injury

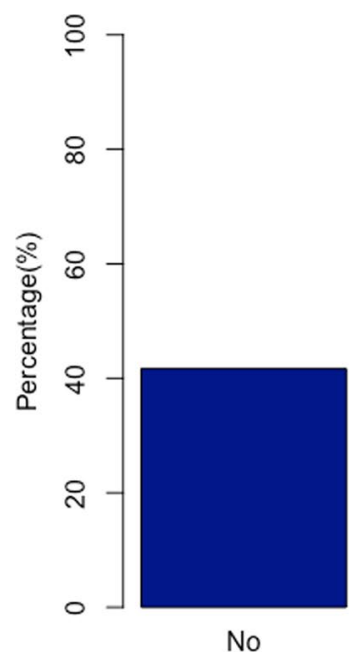

Posterior malleolar fragment on $\mathrm{X}$-rays

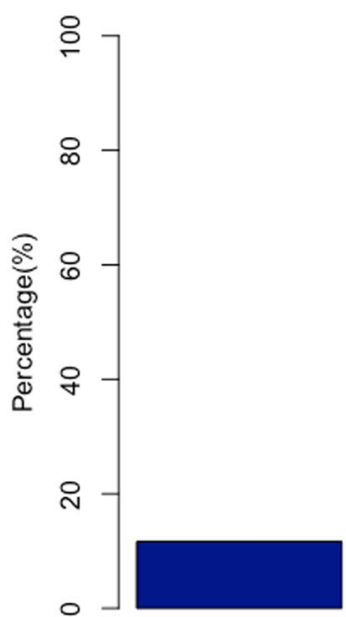

No

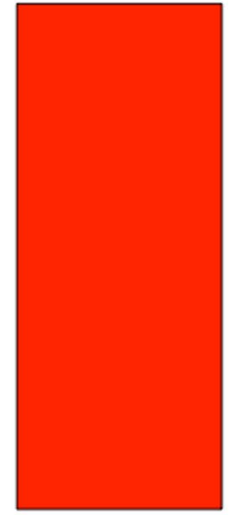

Yes
Posterior malleolar fragment on CT-scan
The original article can be found online at https://doi.org/10.1007/ s00590-021-03104-y.

Pierre-Alban Bouche

pierrealban309@gmail.com

1 Orthopaedic Department, Cochin University Hospital, APHP Paris, Paris Descartes University, 27 rue du Faubourg Saint-Jacques, 75014 Paris, France

2 Orthopaedic Department, Croix St Simon Hospital, 125 rue d'Avron, 75020 Paris, France
Publisher's Note Springer Nature remains neutral with regard to jurisdictional claims in published maps and institutional affiliations. 